\title{
Bio-Organism Damage under the Influence of Microwave Heating
}

\author{
Ziwei Xie \\ 9006 Greenwood Ave, San Gabriel, CA, USA \\ Email: xieziweiisabel@gmail.com
}

How to cite this paper: Xie, Z.W. (2019) Bio-Organism Damage under the Influence of Microwave Heating. Journal of Biosciences and Medicines, 7, 41-45.

https://doi.org/10.4236/jbm.2019.74005

Received: March 11, 2019

Accepted: April 9, 2019

Published: April 12, 2019

Copyright $\odot 2019$ by author(s) and Scientific Research Publishing Inc. This work is licensed under the Creative Commons Attribution International License (CC BY 4.0).

http://creativecommons.org/licenses/by/4.0/

\begin{abstract}
In this paper, we setup a simple model to understand the damage of bio-organism under the influence of microwave heating based on the bio-heat transfer equation and Arrhenius equation. Detailed information of temperature distribution and fraction of damage is presented. Results show that microwave heating is effective in the damage of bio-organism.
\end{abstract}

\section{Keywords}

Bio-Heat, Microwave, Bio-Damage

\section{Introduction}

Radio frequency $(\mathrm{RF}) /$ microwaves has applied in monitoring public health and in medicine as well as being a therapy method [1] [2] [3]. Modern electronic science and technology have seen rapid technological advances and enormous influence on our everyday lives [4]. They have laid the foundation for an unprecedented drive toward the improvement of existing medical devices and for the development of new ones. In particular, the advances in $\mathrm{RF} /$ microwave technology, among others, set the way for novel therapeutic and diagnostic methods. Microwave with frequencies from hundreds of $\mathrm{MHz}$ to several $\mathrm{GHz}$ is of primacy research field being investigated for medical and diagnostic applications in various areas such as cancer therapy, organ imaging, cardiology, surgery, etc. [5] [6] [7] [8] [9]. On the other hand, RF/microwave radiation with high power raised safety concerns on the biological effect. Lots of research has been performed over radio station, television, and digital mobile phone systems [10].

In this manuscript, we study the bio-heating effect of a bio-organism under the illumination of microwave. We set up the microwave and input the bio-heat equation. We setup the bio-organism inside of the microwave, to simulate the 
bio-organism heated. The temperature increase and fraction of damage are both investigated in details. Results show that after $60 \mathrm{~s}$ of microwave illumination, the bio-organism will be $95 \%$ damaged.

\section{Theory and Assumptions}

The heat transferred from the microwave to the bio-organism and the heat dissipation inside the bio-organism is governed by the following heat transfer equation [11].

$$
K \rho C \cdot \partial T / \partial t+\rho C \boldsymbol{u} \cdot \nabla T+\nabla \cdot \boldsymbol{q}-Q=0
$$

where $T$ is the temperature in unit of $K, \rho$ is the density in unit of $\mathrm{kg} / \mathrm{m}^{3}, \mathrm{C}$ is the heat. Capacity in unit of $\mathrm{J} / \mathrm{kg} / \mathrm{K}, \boldsymbol{u}$ is the fluid velocity in unit of $\mathrm{m} / \mathrm{s}, \boldsymbol{q}$ is the heat flux in unit of $\mathrm{W} / \mathrm{m}^{2}$ and $Q$ is the volume heat generation rate in unit of $\mathrm{W} / \mathrm{m}^{3}$.

Here, we also compute the fraction of tissue damage. This parameter gives a quantified evaluation about the degree of tissue injury $(\beta)$ during the process. The calculation is based on the Arrhenius equation [12].

$$
\frac{\mathrm{d} \beta}{\mathrm{d} t}=A \exp \left(-\frac{\Delta E}{R T}\right)
$$

where $\Delta E$ is the activation energy for irreversible damage reaction (in unit of $\mathrm{J} / \mathrm{mol}$ ), and $A$ is the frequency factor (in unit of $\mathrm{Hz}$ ). These two parameters are dependent on the type of tissue under study. The fraction of damaged tissue $(\eta)$ is represented by: $\eta=1-\exp (-\beta)$.

\section{Results and Discussions}

The setup of the simulation under study is shown in Figure 1. The isolated box is $40 \mathrm{~cm}$ long, $40 \mathrm{~cm}$ wide and $20 \mathrm{~cm}$ high, used for confining the microwave inside. Besides, the box is made of copper, a good material for being low loss in the microwave range under study. The bio-organism is represented by an ellipsoid with three semi-axes being 8,5 and $3 \mathrm{~cm}$ long. Specifically, we choose three points in the central plane for measuring the detailed information in the bio-organism. They are denoted by A, B and C as the inset of Figure 1. The microwave is sent from the port on the left side to excite the simulation.

Figure 2 is the temperature distribution of the bio-organism at different times (a) $10 \mathrm{~s}$, (b) $30 \mathrm{~s}$, (c) $45 \mathrm{~s}$, and (d) $60 \mathrm{~s}$. At $10 \mathrm{~s}$, the bio-organism stays mostly at its initial temperature since there are not enough energy being absorbed. The temperature increases gradually as the absorbed energy increases. At $60 \mathrm{~s}$, the highest temperature rises to $305 \mathrm{~K}, 5$ degrees higher than its initial value.

This study is simulation the bio-organism damage under the bio-heat. In life, skin scald and cooking are example of bio-organism damage.

Figure 3 gives the temperature as a function of time at the designated points. The temperature increases at a much higher rate for Point $\mathrm{B}$ as a microwave hot spot is formed around Point B, offering much more energy density.

Finally, we study the fraction of damaged bio-organism according to the Arrhenius equation discussed above. Figure 4 shows the fraction of damage for the 


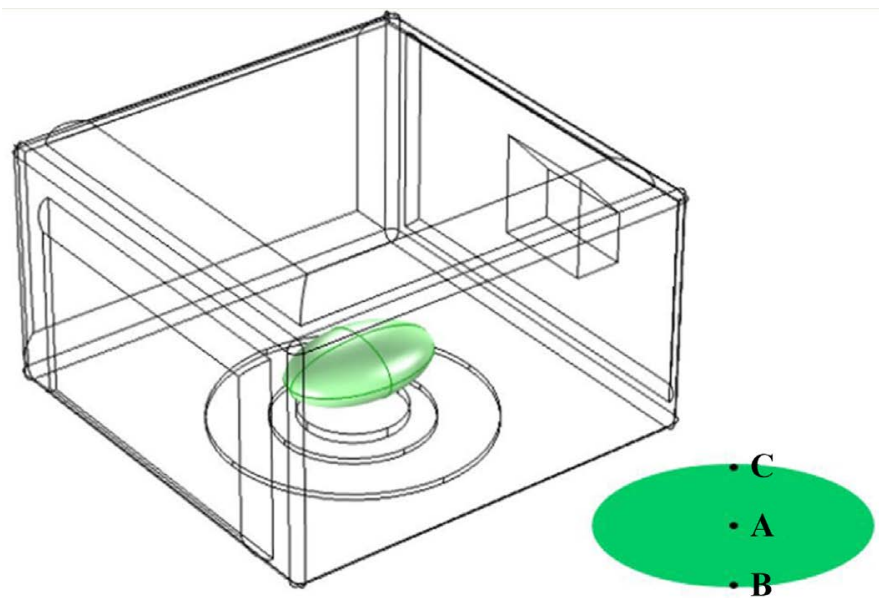

Figure 1. The bio-organism is located inside a metal box under the illumination of microwave. Three points located at the central plane of the bio-organism (shown in the lower right inset) are chosen to monitor the temperature and fraction of damage. (C point is center point of the upper surface, B point is center point of the surface below. A point is the central of whole bio-organism.)

(a)

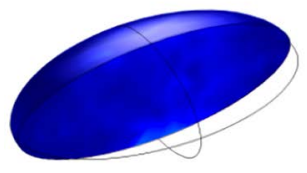

(c)

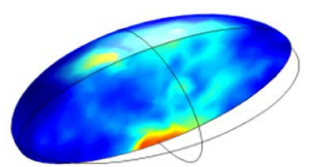

(b)

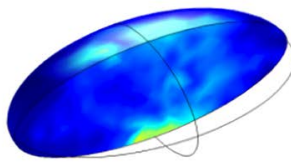

(d)

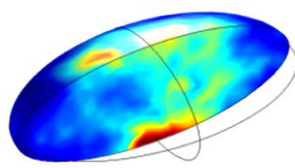

$305 \mathrm{~K}$

$300 \mathrm{~K}$

Figure 2. Temperature distribution of the bio-organism at different times: (a) $10 \mathrm{~s}$, (b) 30 s, (c) $45 \mathrm{~s}$, (d) $60 \mathrm{~s}$.

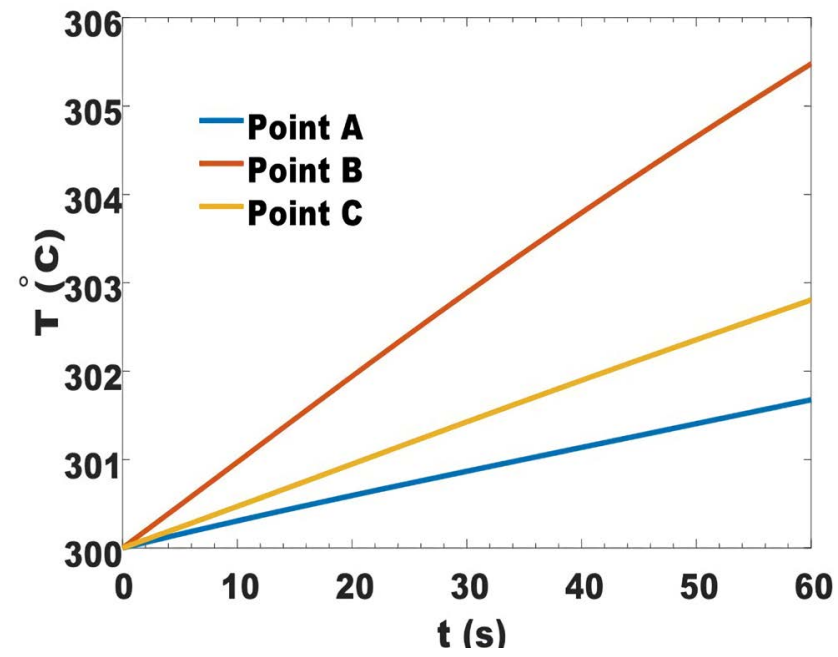

Figure 3. Temperature as a function of time at designated points. 
(a)

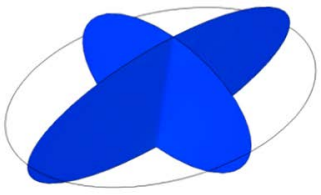

(c)

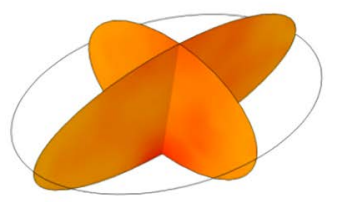

(b)

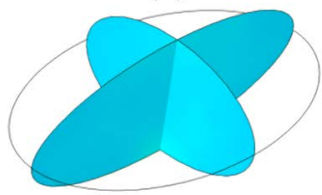

(d)

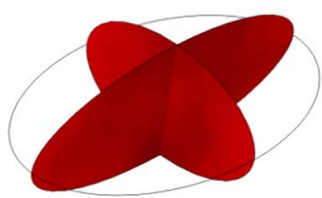

$100 \%$

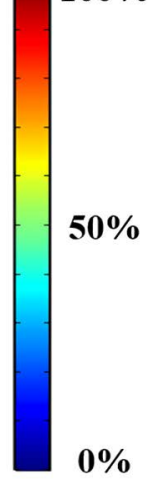

Figure 4. Fraction of damage for the bio-organism at (a) $5 \mathrm{~s}$, (b) $10 \mathrm{~s}$, (c) $30 \mathrm{~s}$, and (d) $60 \mathrm{~s}$.

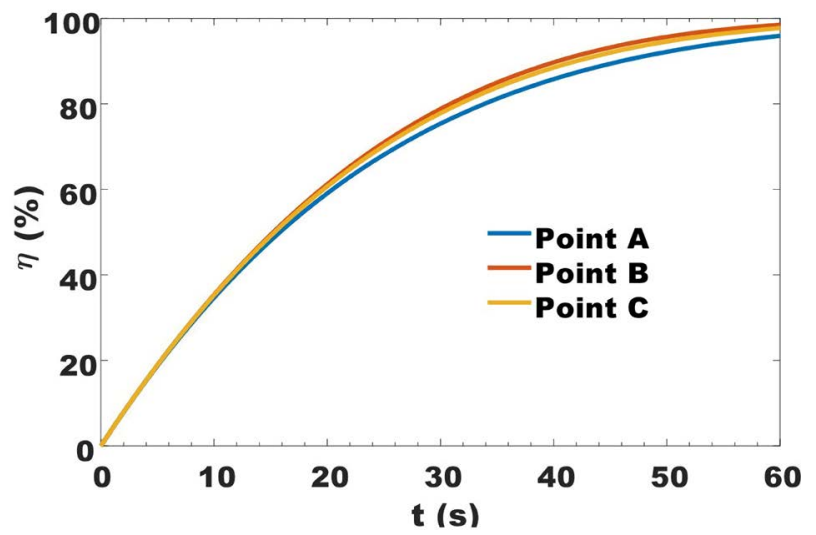

Figure 5. Fraction of damage for the designated points as a function of time.

bio-organism at different times for the two cross sectional view long the central line. The corresponding values are $15 \%, 35 \%, 75 \%$ and $95 \%$. Note that the damage is relatively uniform on the planes displayed. Fraction of damage for the designated points as a function of time is shown in Figure 5. The value increases quickly in the first 30 seconds and slows down thereafter, gradually saturates towards $100 \%$.

\section{Summary}

In conclusion, we have established a model for studying the bio-heating effect under microwave. The model simulation is based on the heat transfer equation and Arrhenius equation. Simulation results reveal that the bio-organism will rise 5 degrees in temperature and $95 \%$ will be damaged by the microwave radiation.

\section{Conflicts of Interest}

The author declares no conflicts of interest regarding the publication of this paper.

\section{References}

[1] Chandra, R., Zhou, H., Balasingham, I. and Narayanan, R.M. (2015) On the Op- 
portunities and Challenges in Microwave Medical Sensing and Imaging. IEEE Transactions on Biomedical Engineering, 62, 1667-1682. https://doi.org/10.1109/TBME.2015.2432137

[2] Cheng, G.G., Zhu, Y. and Grzesik, J. (2013) Microwave Medical Imaging Techniques. 2013 th European Conference on Antennas and Propagation (EuCAP), Gothenburg, 8-12 April 2013, 2669-2673.

[3] Livraghi, T., Meloni, F., Solbiati, L., Zanus, G. and Collaborative Italian Group Using AMICA System (2012) Complications of Microwave Ablation for Liver Tumors: Results of a Multicenter Study. Cardiovascular and Interventional Radiology, 35, 868-874. https://doi.org/10.1007/s00270-011-0241-8

[4] Einspruch, N.G., Ed. (2014) VLSI Electronics: Microstructure Science (Vol. 3). Academic Press, New York.

[5] Rosen, A. (1990) Microwave Application in Cancer Therapy, Cardiology and Measurement Techniques: A Short Overview. IEEE MTT Newsletter, 17-20.

[6] Finger, P.T, (1997) Microwave Thermoradiotherapy for Uveal Melanoma: Results of a 10-Year Study. Ophthalmology, 104, 1794-1803.

https://doi.org/10.1016/S0161-6420(97)30024-4

[7] Strohbehn, J.W., Bowers, E.D., Walsh, J.E. and Douple, E.B. (1979) An Invasive Microwave Antenna for Locally-Induced Hyperthermia for Cancer Therapy. The Journal of Microwave Power, 14, 339-350. https://doi.org/10.1080/16070658.1979.11689169

[8] Tabuse, K. (1998) Basic Knowledge of a Microwave Tissue Coagulator and Its Clinical Applications. Journal of Hepato-Biliary-Pancreatic Surgery, 5, 165-172. https://doi.org/10.1007/s005340050028

[9] Nikolova, N.K. (2011) Microwave Imaging for Breast Cancer. IEEE Microwave Magazine, 12, 78-94. https://doi.org/10.1109/MMM.2011.942702

[10] Hossmann, K.A. and Hermann, D.M. (2003) Effects of Electromagnetic Radiation of Mobile Phones on the Central Nervous System. Bioelectromagnetics, 24, 49-62. https://doi.org/10.1002/bem.10068

[11] Bravo, M.E., Sánchez, P.D.J., Aguilar, R.V. and Chávez, A.E. (2015) Heat Transfer in Biological Tissues. In: Selected Topics of Computational and Experimental Fluid Mechanics, Springer, Cham, 313-320. https://doi.org/10.1007/978-3-319-11487-3_21

[12] Vander Vorst, A., Rosen, A. and Kotsuka, Y. (2006) RF/Microwave Interaction with Biological Tissues (Vol. 181). John Wiley \& Sons, New York. 